\title{
Hepcidin, an emerging and important player in brain iron homeostasis
}

\author{
Driton Vela*
}

\begin{abstract}
Hepcidin is emerging as a new important factor in brain iron homeostasis. Studies suggest that there are two sources of hepcidin in the brain; one is local and the other comes from the circulation. Little is known about the molecular mediators of local hepcidin expression, but inflammation and iron-load have been shown to induce hepcidin expression in the brain. The most important source of hepcidin in the brain are glial cells. Role of hepcidin in brain functions has been observed during neuronal iron-load and brain hemorrhage, where secretion of abundant hepcidin is related with the severity of brain damage. This damage can be reversed by blocking systemic and local hepcidin secretion. Studies have yet to unveil its role in other brain conditions, but the rationale exists, since these conditions are characterized by overexpression of the factors that stimulate brain hepcidin expression, such as inflammation, hypoxia and iron-overload.
\end{abstract}

Keywords: Hepcidin, Astrocytes, Inflammation, Brain hemorrhage, Alzheimer's disease

\section{Background}

Hepcidin has been subject of increased interest from researchers ever since its discovery in 1998, and especially since 2001, when Pigeon et al. discovered its crucial role in iron homeostasis [1]. The most important data about its actions and regulation come from studies that have examined the liver isoform of this peptide. Liver hepcidin is the most abundant source of systemic hepcidin, but data suggest that not only hepcidin is produced locally in different organs, but local isoforms can serve important functions for organ homeostasis as well [2-4].

\section{Systemic iron metabolism}

Humans secure iron from different food sources. Dietary iron is absorbed through the intestines, that is, enterocytes, after being reduced by apical ferrireductases [5]. Divalent iron then enters in enterocytes through divalent metal transporter 1 (DMT1). Inside enterocytes iron is transported via poly-(rC)-binding proteins (PCBPs) to iron depots (ferritin) and molecules that use iron as a cofactor [6]. It is still not entirely known if PCBPs deliver

\footnotetext{
${ }^{*}$ Correspondence: driton.vela@uni-pr.edu

Department of Physiology, Faculty of Medicine, University of Prishtina, Martyr's Boulevard n.n., 10000 Prishtina, Kosova
}

iron to ferroportin (FPN), but we know that FPN acts as the major iron-exporter out of cells $[5,6]$. During its efflux out of enterocytes iron is oxidized and immediately bound to transferrin (Tf) [5]. Tf-iron complex circulates in the blood and finally binds with transferrin receptor 1 (TFR1) receptor in target cells. Cellular iron availability is controlled by iron regulatory element/iron regulatory protein (IRE/IRP) system, which is reactive to cellular iron concentrations [5, 6]. IRE/IRP is able to control cellular iron homeostasis by controlling the expression of cellular iron importers and exporters [5, 6]. It is evident that in every stage of iron transport, iron tends to be bound with different proteins, which serves as a protective mechanism that does not allow iron access to pathogenic microbes [5]. In addition, iron is a highly reactive element which might cause oxidative stress in our cells, therefore the chemical modification of iron by reductases and its transport realized through binding with different proteins, like ferritin (intracellularly) and Tf (extracellularly) protects tissues from oxidative damage $[5,6]$.

\section{Liver hepcidin acts as a major regulator of systemic iron metabolism}

Hepcidin is a small peptide with antimicrobial properties. It affects systemic iron availability by controlling FPN 
expression post-translationally [5]. It is mostly produced by liver sinusoidal endothelial cells (LSECs) in response to iron-load [7]. Iron-load induces production of bone morphogenetic protein 6 (BMP6) from LSECs, which then acts in neighbouring hepatocytes through BMP receptor (BMPR) [8] (Fig. 1). BMPR creates a supercomplex with hemojuvelin (HJV), matriptase 2 (MT2) and neogenin [9]. This scaffold of molecules controls the activity of BMPR. Once activated, BMPR induces phosphorylation of s-mothers against decapentaplegic (SMAD) molecules, which then cause an increase in hepcidin expression through activation of hepcidin antimicrobial peptide $(H A M P)$ gene [5]. Iron-mediated pathways induce hepcidin expression through other membrane proteins, such as TFR2 and HFE, with HFE being less important in this context [10]. Other positive stimuli that control hepcidin expression are inflammatory stimuli, which act through janus kinase 2/signal transducer and activator of transcription 3 (JAK2/STAT3) pathway [5]. Overactivity of inflammatory cytokines is responsible for anemia of inflammation in different chronic diseases and cancer $[5,11]$. Negative control of hepcidin expression is exerted by erythroferrone (ERFE) which is produced by erythrocyte precursors in order to secure more iron for erythropoiesis [12]. Other factors that have been shown to affect hepcidin expression include vitamin D, hypoxia, heparin, estrogens [13-16].

Hepcidin produced by the liver acts on its target cells, like enterocytes, macrophages, hepatocytes, and as recent data suggest, in brain cells as well $[17,18]$.

\section{Brain iron metabolism}

Iron turnover in the brain is slow compared to other organs [19]. The process of iron uptake starts in the level of blood-brain barrier (BBB), where first cells to come into contact with Tf-iron complex are brain microvascular endothelial cells (BMVECs) [20]. Tight junctions between these cells preclude an iron-entry through paracellular pathways, leaving the option of transcellular pathway as the most viable one. In this way BMVECs exert a strict control on brain iron-uptake by regulating the level of receptors through which iron enters and exits BBB [20]. Tf-iron enters BMVEC through its receptor, that is, TFR [21]. Blocking TFR with specific antibodies reduces significantly the ability of BMVEC to transport iron [22]. Nevertheless, Tf-iron complex with TFR creates an endosome which will then release the reduced iron into cytoplasm via DMT1 $[20,21]$. DMT1 is believed to be also responsible for non-transferrin bound iron (NTBI) entry into BMVEC by serving as a direct iron importer in the luminal surface of BMVEC [20]. Both sources of iron exit BMVEC through FPN [20]. Activity of BMVEC FPN is dependent on the presence of two ferrioxidases, hephaestin (heph) and ceruloplasmin (CP) [20]. Although iron distribution from BMVEC to brain tissue cells is not yet clear, it seems to be rather effective since systemic iron deficiency does not cause significant reduction in brain iron depots [23]. In-vivo experiments show that astrocytes are important mediators of iron transport from BMVEC to brain tissue [21]. They secrete ferroxidases that stabilize BMVEC FPN, but also are an important source of local hepcidin through which they control iron entry into brain tissue [21, 24]. Astrocytes are also important local regulators of neuron homeostasis by sequestering excess iron during iron-overload [25-27]. After crossing the BBB barrier iron is used for its metabolic needs by neurons. It enters neuronal cells through TFR and DMT1 [28]. These two proteins are believed to be more prominently expressed in neurons compared to glial cells [29]. Recent data suggest that transport of NTBI in brain cells is dependent on newly described proteins, that is, Zip8 and Steap2 [30], though the exact role of these proteins in brain iron metabolism remains to be elucidated.

\section{Hepcidin production and action in the brain}

First studies that have examined hepcidin expression in the brain yielded somewhat different results. According to Krause et al. hepcidin expression in the brain is low but still third next to liver and heart [31]. Other studies found that this expression was even lower than the previous study suggested [1,32]. In another study, which examined mRNA and protein levels of hepcidin, results showed a marked discrepancy between these two markers of hepcidin presence, with protein levels being more pronounced than mRNA levels of hepcidin [33]. These results were similar with observations from Zechel et al. study [32], where data from in situ hybridization (which measured mRNA expression) did not match results from immunohistochemistry (which measured protein distribution) (Table 1). These data imply that at least some of hepcidin in the brain in fact comes from liver [33]. mRNA of hepcidin is not uniformly expressed in different regions of rat brain; higher mRNA is observed in cortex, striatum, cerebellum [32, 34], while others failed to detect mRNA in cortex [33], though protein levels of hepcidin were found in choroid plexus, corpus callosum, olfactory bulb, cortex, subventricular zone [33, 35]. The differences in mRNA expression seem to have been related to the sensitivity of the methods used to detect hepcidin expression (RT-PCR vs in situ hybridization). Hepcidin protein has also been observed in mature astrocytes, especially in those localized in the walls of lateral ventricle [35]. Chowdhury et al. study has revealed that hepcidin protein is present in glial cells, but not in mature neurons [35]. All these observations show that hepcidin 


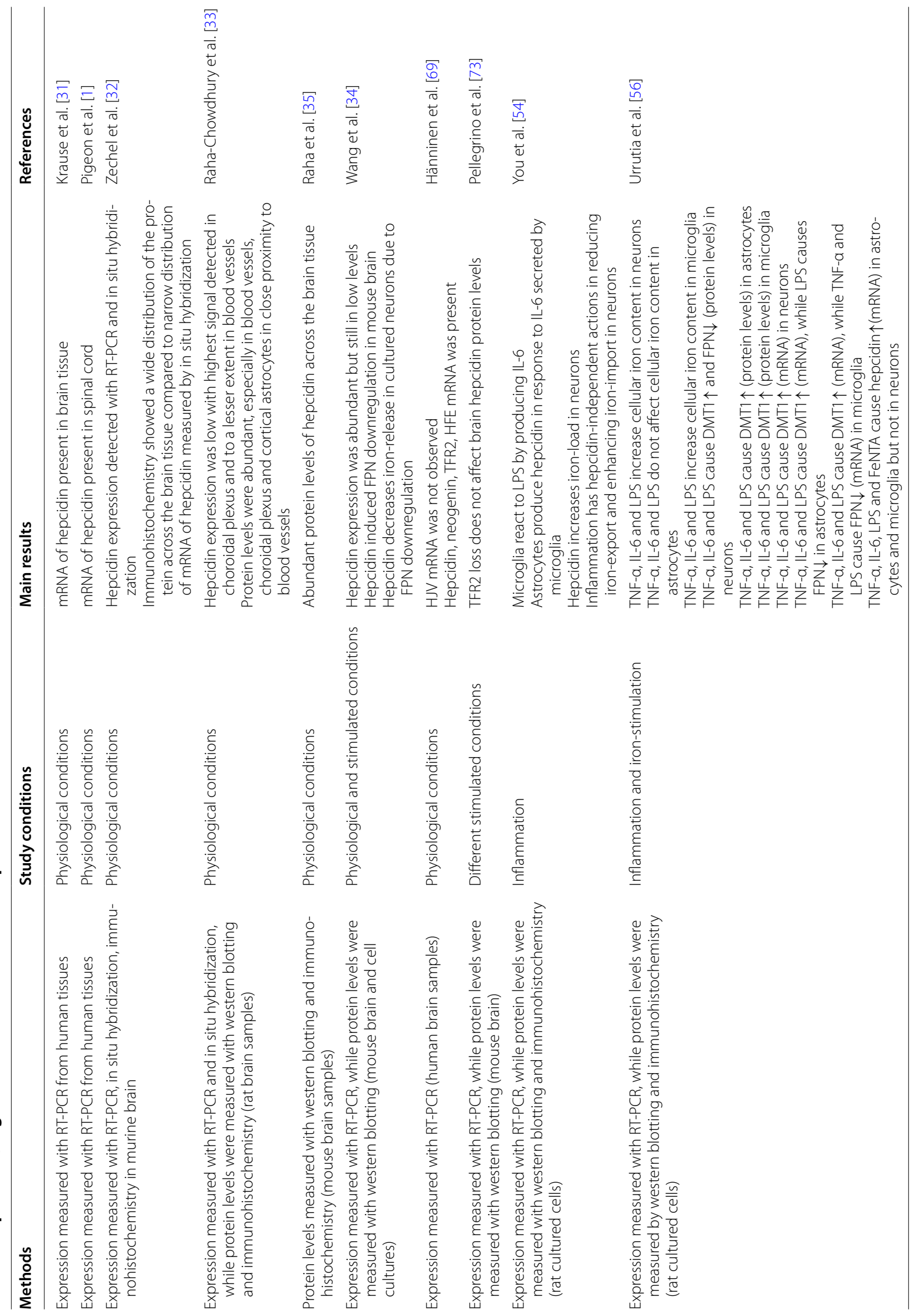




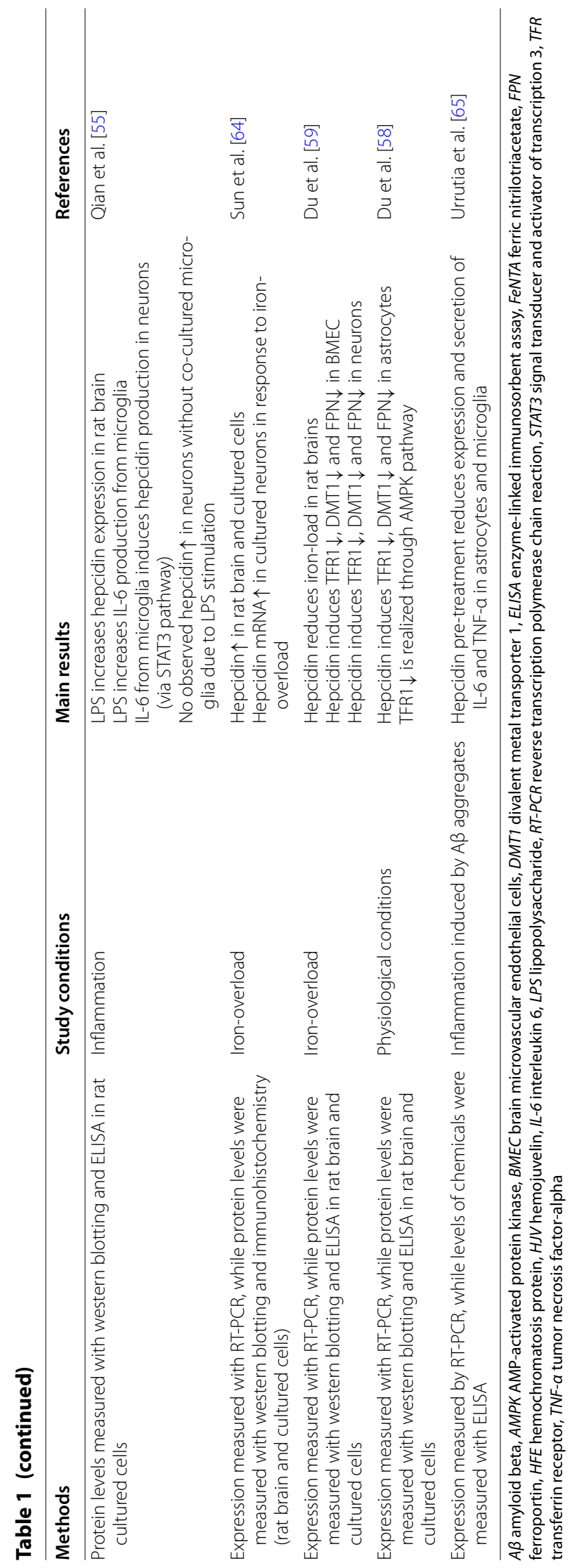


expression in the brain is low in basal conditions. The presence of hepcidin in vascular structures and cellular components of BBB shows that the hepcidin role in basal conditions might include the control of iron entry from plasma into the brain. But, it seems that systemic hepcidin is redundant in controlling brain iron homeostasis in basal conditions. In liver (systemic) hepcidin knockout mice brain iron is not significantly altered [18]. In hemochromatosis $(\mathrm{HH})$, which is associated with hepcidin disturbance, brain iron-load is a seldom occurrence [36], mostly present when accompanied with abnormally high levels of ferritin and transferrin saturation, or liver cirrhosis, in which condition iron can pass more freely in brain parenchyma due to BBB disruption [37-39]. In conclusion, systemic hepcidin loss not accompanied by additional deleterious factors does not seem to cause significant brain iron-load. This is further strengthened by observations that brain iron-overload in $\mathrm{HH}$ is more frequently present in progressive and terminal stages of the disease [38]. Since iron is indispensable for brain homeostasis, neurons have evolved important strategies to counteract local iron disturbance. During iron-overload neurons increase ferritin to sequester iron in nontoxic form, downregulate iron importers and increase iron export [40]. Furthermore, astrocytes increase their iron-import during iron-overload to protect neurons from damage [27]. Intrinsic iron regulation in the brain does seem to compensate for the loss of systemic hepcidin. Similar protective mechanisms have been observed in retina as well.

Though hepcidin is present in all the cells that comprise the $\mathrm{BBB}$, less is known about the hepcidin transport through BBB. Defensins and amphipathic peptide cations similar to hepcidin are known to cross BBB $[41,42]$. Hepcidin transport through $\mathrm{BBB}$ has not been observed directly, but hepcidin protein has been detected in the brains of mice with knockdown of systemic hepcidin after being transfused with hepcidin [18].

More consistently hepcidin expression has been detected in special function neurons such as retinal photoreceptors, but also in retinal pigment epithelium (RPE) and adjacent Muller cells [43]. Similar to LSECs in the liver, RPE produces BMP6 in response to iron-load which then induces hepcidin expression in neurosensory retina $[44,45]$. Interestingly, neurosensory retinal cells express more abundant BMP receptor expression compared to RPE, suggesting that BMP6 from RPE acts on BMPR of neurosensory retinal cells. HJV seems to be important in inducing hepcidin expression in RPE, since loss of HJV in RPE cells blunts the hepcidin expression due to ironload [46]. Hepcidin produced by retinal cells during ironoverload acts in a paracrine manner by degrading FPN in neighbouring vascular endothelial cells, thus preventing retinal iron import [45]. On the other hand, eye injury does induce hepcidin expression in retinal cells through interleukin-6 (IL-6) mediation [45]. Furthermore, in vivo and in vitro studies have shown that inflammatory stimuli induce hepcidin expression in RPE and neural retina [43]. Retinal hepcidin overexpression due to inflammatory stimuli is accompanied with cellular iron-overload and increased oxidative stress [43]. Inflammatory signaling in retina induces hepcidin independent of HFE and HJV. This action is mediated through activation of Toll-like receptor 4 (TLR4) in RPE [43]. Systemic hepcidin does not seem to have an important role in retina in basal conditions, which is suggested by the presence of significant iron-overload in retina only in aged rats with loss of hepcidin and HJV [45, 46]. It has to be mentioned that in juvenile $\mathrm{HH}$ caused by a dramatic loss of hepcidin expression, organ iron-overload (heart, liver, gonads) is observed early in life [47]. Incidence of retinal damage in $\mathrm{HH}$ is low [48], while mice models with FPN knockout show early and more prominent retinal damage compared to systemic hepcidin knockout [49]. This suggests that local FPN in retina is more important for iron homeostasis than systemic hepcidin levels.

\section{Hepcidin regulation in the brain}

Inflammation is an important inducer of local brain hepcidin expression. It can induce a significant increase in brain hepcidin expression (even up to 40-fold increase during E. coli infection) [50]. In epithelial cells of the choroidal plexus injection of bacterial lipopolysaccharide (LPS) induces upregulation of IL-6 and HAMP [51]. IL-6 upregulation is accompanied with expected STAT3 upregulation, which causes an increase in hepcidin expression [51]. Interestingly, LPS causes increased SMAD4 expression as well, which may be related with increased TFR2 expression [51]. These changes accompanied with increased ferritin expression suggest that inflammatory stimuli prevent iron export into cerebrospinal fluid (CSF) and cause iron accumulation in epithelial cells of choroidal plexus. LPS and IL-6 have consistently been related with increase in hepcidin expression in brain parenchyma as well $[50,52,53]$. Experiments with cell cultures have shown that LPS induces IL- 6 expression in microglia, which then induces hepcidin production in astrocytes and probably neurons $[54,55]$. LPS can induce hepcidin production in microglia as well $[56,57]$, while IL-6 was shown to increase hepcidin expression in neurons through phosphorylation of STAT3 [55]. Studies with cell cultures have revealed that, in astrocytes and neurons, hepcidin induces not only FPN downregulation, but also TFR1 and DMT1 downregulation $[58,59]$. This is interesting since this would mean that hepcidin not only controls iron export, but iron import as well. This action 
of hepcidin might include an interaction with a new hepcidin receptor in astrocytes, which activates AMPactivated kinase (AMPK) intracellularly [58]. According to You et al. [54] microglia do not increase hepcidin expression in response to inflammatory stimuli, but they do increase IL-6 significantly, more so than astrocytes. Hepcidin released from astrocytes downregulates FPN expression in neurons [54, 56] (Fig. 2). There seems to be some contradiction if hepcidin actions on FPN protect neurons from iron-overload, or they cause apoptosis through increased oxidative stress [54, 56, 59-61]. Studies which suggested that hepcidin induces apoptosis in neurons through increased iron-load, were realized in models of brain ischemia and inflammation. Ischemia induces increased expression of TFR1, which increases iron import into cells [52]. Inflammation also increases iron sequestration in neurons, because it causes upregulation of DMT1 [56], which is an iron importer, though other studies contest these changes [54]. Studies that reported no change in expression of TFR1 and DMT1 during inflammation only evaluated the role of LPS during inflammation [54], but not of other important inflammatory cytokines, such as tumor necrosis factor-alpha (TNF- $\alpha)$. This is important since DMT1 overexpression in the brain in response to TNF- $\alpha$ has been consistently observed in models of inflammation in the brain $[27,56$, 62]. In terms of iron transport, inflammation in the brain does seem to tip the balance in favor of increased cellular iron sequestration. An important issue stemming from Urrutia et al. study [56], is the level of FPN downregulation observed in neurons due to inflammatory stimuli; TNF- $\alpha$, LPS and especially IL-6 induce a robust downregulation of FPN protein levels in neurons compared to untreated control, irrespective of hepcidin action. Similar results were obtained by Zhang et al. study where proinflammatory cytokines reduced FPN expression in dopaminegic neurons [63]. You et al. study [54] did not find any significant changes in TFR1 and DMT1 levels in neurons due to LPS treatment and attributed iron accumulation in neurons due to FPN downregulation, which could be related with marked FPN downregulation caused by inflammatory stimuli. On the other hand, Urrutia et al. did observe increase in DMT1 expression in neurons, but this was not as robust as FPN downregulation [56]. This study also found that LPS induced a less pronounced DMT1 upregulation compared to IL- 6 and TNF- $\alpha$. It has to be mentioned that You et al. did not examine effects of IL- 6 and TNF- $\alpha$ on DMT1 levels. Another difference between You et al. and Urrutia et al. studies is that You et al. did not observe hepcidin overexpression in microglia and astrocytes due to LPS stimulation, but Urrutia et al. did. Also, Urrutia et al. observed increased hepcidin expression in astrocytes and microglia due to IL-6, but You et al. observed increased hepcidin expression only in astrocytes due to IL-6. These discrepancies might have occurred due to different strains of rodents or different methods of LPS treatment used by the authors. But, Urrutia et al. is in-line with You et al. study when concluding that astrocytes are the major cellular inducers of hepcidin due to inflammatory stimuli. These results suggest that at least during inflammation neurons are not the source of hepcidin expression. Another issue that remains to be resolved is if neurons increase hepcidin expression due to iron-load. Although iron-load can induce hepcidin expression in astrocytes and microglia, there is disagreement if this action occurs in neurons [56, 64]. Subtle differences observed between studies might explain these results; for example, increase in neuronal hepcidin expression was observed after $4 \mathrm{~h}$ of treatment with higher doses of iron therapy, whereas Urrutia et al. did not obtain these results probably due to lower levels of iron supplementation used or due to early measurements of hepcidin expression (2 h). Future research should clarify this important issue.

New research suggests that pretreatment with hepcidin downregulates markers of inflammation and oxidative stress in activated astrocytes and microglia by amyloid- $\beta$ $(A \beta)$, which protects neurons from cellular damage [65]. This is due to hepcidin ability to downregulate inflammatory stimuli. This is not the first time that hepcidin is associated with antiinflammatory response. De Domenico et al. study [66] showed that hepcidin pretreatment reduces the ability of LPS to induce cytokine production. This action of hepcidin is mediated through inhibition of IL- 6 and TNF- $\alpha$ via suppressor of cytokine signaling 3 (SOCS3). The role of hepcidin in controlling antiinflammatory response is further strengthened by Burté et al. study [67], where higher levels of hepcidin were associated with better outcome during malaria infection. Role of hepcidin as an antiinflammatory peptide might serve as the "closing act" of the feedback loop that controls the inflammatory response. This new role of hepcidin is intriguing and it is surprising that it has not been examined more extensively.

In physiological conditions hepcidin induces downregulation of iron importers in neurons [59]. This would be the reason why hepcidin protects neurons from ironoverload [60,61]. Neurons compared to glial cells express much higher levels of DMT1 in physiological conditions [29]. This means that in neurons cellular iron-load can be significantly affected by iron import(ers). There are suggestions that the protective effects of increased hepcidin production might occur not just as a result of hepcidin actions on neuronal cells, but also due to its actions on endothelial cells of the BBB [59]. These actions would result in decreased iron entry in brain cells. Indeed, 
iron-loaded astrocytes act in neighbouring endothelial cells of the BBB by reducing the expression of TFR, thus impairing iron-transport through BBB [68]. This action of astrocytes is realized through hepcidin according to in vitro animal models [68].

It is still not known how iron-load induces hepcidin expression in brain cells. It seems that membrane HJV has a redundant role in this context, since its expression is nonexistent in the brain $[69,70]$. Other regulatory factors of hepcidin expression, like neogenin, are expressed in the brain, but their role in controlling hepcidin expression in brain cells is unknown [69]. The main chemical signal that induces hepcidin expression in the liver, BMP6, is expressed in the brain [71, 72]. In models with Alzheimers disease (AD), BMP6 is upregulated (compared to low levels of hepcidin observed in AD) and related with impaired neurogenesis [35, 72]. In models of ischemia BMP6 has shown to have protective effects on brain tissue compared to hepcidin [71]. This shows that BMP6 does not control hepcidin expression in models of ischemia/inflammation, but if BMP6 controls hepcidin expression in the brain in response to iron-load is still an unexplained issue. Finally, TFR2 expression has also been observed in brain tissue, but it does not seem to impact hepcidin expression [73].

\section{Hepcidin in brain diseases}

\section{Hepcidin in AD and Parkinsons disease (PD)}

Most of brain iron in early age is sequestered in oligodendrocytes, but with increasing age iron is more prominently deposited in astrocytes and neurons, whose iron levels are low in early age [74]. Iron is important for brain cells because it is used to maintain their metabolic needs, but also for myelin synthesis and neurotransmitter production [75].

In a study with brain samples from humans with $\mathrm{AD}$ taken during autopsy, levels of hepcidin and FPN were low, and the same result was observed in the accompanied rat models of AD [35]. Hepcidin levels, according to mice models, exhibited changes in later stages of the disease, but not in the early stages of the disease (Table 2). These changes seem to be secondary and related to neuronal damage. It is interesting to notice that $\mathrm{AD}$ is mostly associated with advanced age [75], while increased hepcidin expression has been observed in aged rats and it is still not known why [76]. On the other hand, hepcidin localization in the brain of AD patients is related closely with the localization of amyloid plaques [35].

Increased hepcidin without the change in FPN levels shows that with advancing age hepcidin cannot change the levels of FPN expression significantly [75]. It might be that the "culprit" behind these observations is ironload, which has been shown to induce FPN transcription.
Unfortunately, AD models with hepcidin knockouts have not been studied, in order to understand the role of hepcidin in this disease [77]. These models should focus on examining the role of hepcidin in early stages of the disease and identifying the cellular source of the hepcidin, which presumably should include astrocytes or microglia.

Oxidative damage is thought to be an important pathogenic factor in $\mathrm{AD}$, especially in early stages of the disease $[78,79]$. It is not known which is the source of oxidative damage in early AD, but iron deposition is a strong candidate. Excess iron has been observed in AD. Hipoccampal, basal ganglia, cortical samples from AD patients show increased levels of ferritin iron [80, 81]. Amyloid plaques in $\mathrm{AD}$ are associated with iron deposition, as well as with iron-overloaded microglia [82]. Furthermore, iron-loading has been shown to accelerate plaque toxicity, while iron-chelation reverses these changes [83]. This is important since amyloid accumulation has been observed in a large proportion of persons without cognitive abnormalities, which means that additional factors (such as iron-induced toxicity) might turn benign amyloid aggregates into brain damaging factors. Cellular iron sequestration in the brain of $\mathrm{AD}$ patients could happen due to disturbance in iron transport, disruption of $\mathrm{BBB}$ or due to micro-hemorrhages observed in AD [84]. The $\beta$-amyloid precursor, amyloid precursor protein (APP), interacts with FPN and in this way controls iron export [85]. Loss of APP causes iron retention [85]. In AD, APP mRNA is downregulated, while it has been shown that APP stabilizes FPN in neuronal membrane $[85,86]$.

APP downregulation in AD is accompanied with DMT1 upregulation [87]. DMT1 is co-localized with amyloid plaques, while overexpression of APP is related with DMT1 overexpression [87]. Crucially, downregulation of DMT1 with siRNA causes downregulation of APP and reduction in secretion of A $\beta$ [87]. Recent data suggest a potential role of hepcidin in AD pathophysiology. In-line with this suggestion is the observation from genetic studies where specific genetic variations that cause a decreased expression of FPN are a risk factor for $\mathrm{AD}$ [88]. On the other hand, the genetic variant that offered most protection was related with increased expression of FPN. Furthermore, in vitro studies suggest that oxidative damage, which is induced during AD, can be ameliorated with hepcidin injections [59, 60]. Hepcidin injections reduce inflammatory markers in astrocytes and microglia treated with $A \beta$ [65]. By ameliorating two of the most important pathogenic factors in AD, like oxidative damage and inflammatory process, hepcidin could prove to be a novel therapeutic agent in AD. Also, knockdown of hepcidin in activated astrocytes by inflammatory stimuli prevents iron-load and reduces apoptosis in neurons [54]. It seems that the relationship between iron 


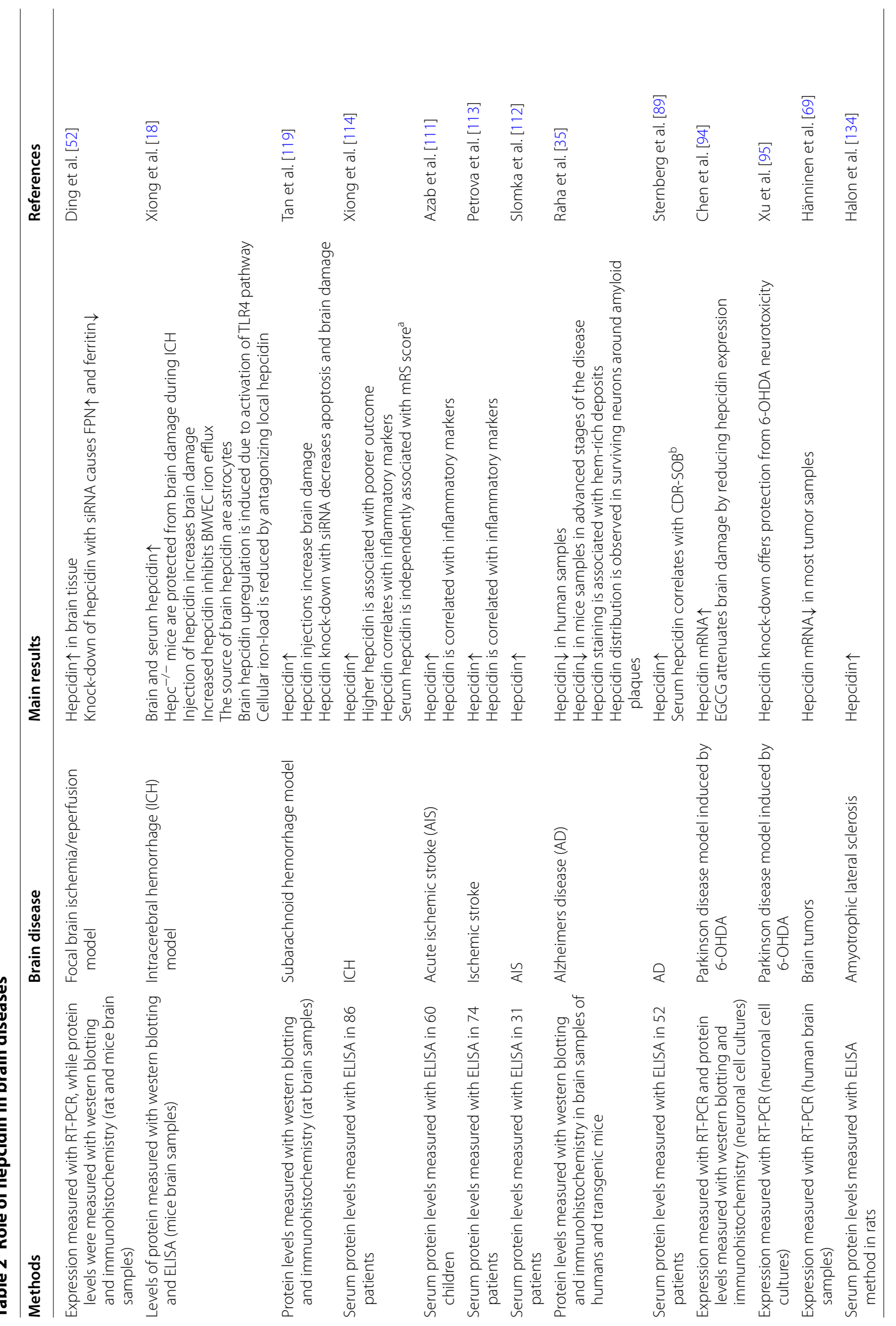




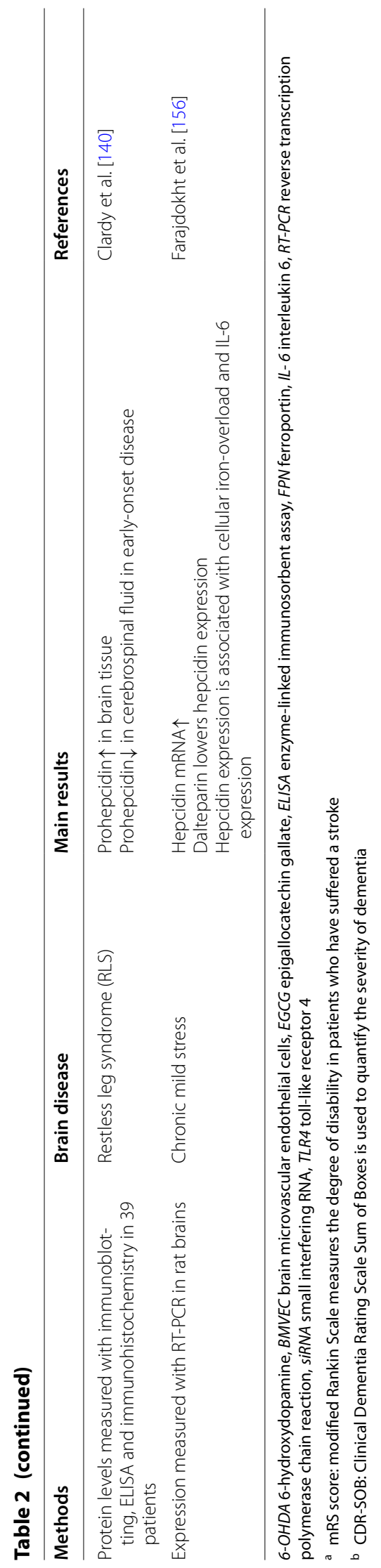


importers/exporters is important in controlling iron-load in neurons. In noninflammatory conditions, hepcidin reduces iron-load because it reduces iron-import into neurons and from blood vessels into brain parenchyma. During inflammation the increase in iron-import coupled with reduction in iron-export increases the iron-load in neurons. This means that iron-load will be ameliorated by restoring iron-export (through hepcidin knockdown). Since high levels of inflammation are related to neuronal iron-overload, it would be interesting to examine how does generally low levels of brain inflammation in $\mathrm{AD}$ "compete" with dose-dependent actions of hepcidin in neurons.

Hepcidin disturbance in AD has recently been suggested to have a systemic nature as well. Serum levels of hepcidin are higher in $\mathrm{AD}$ and are related with severity of the disease [89]. Since serum hepcidin can pass BBB, it might affect iron-export into brain parenchyma through regulation of FPN. This hypothesis needs confirmation from proper experimental AD models with systemic hepcidin knockout.

Iron dysregulation has been observed in PD patients as well. Iron-load in these patients (similar to AD patients) is localized in specific structures such as substantia nigra, red nuclei, globus pallidus, with early changes observed in substantia nigra, but not in other structures [90,91]. In $\mathrm{AD}$ patients with associated $\mathrm{PD}$ (35-40\% of patients) iron-load in substantia nigra is higher than in $A D$ alone [92].

Inflammation and oxidative stress are both present in PD [93]. In rat models of PD induced by 6-hidroxydopamine (6-OHDA), hepcidin expression induces ironload in neurons, while hepcidin knockdown reduces the iron-load [94, 95]. It is interestingly to notice that in rat models, 6-OHDA induces upregulation of DMT1 and hepcidin, which results in increased iron entry into cells and decreased iron export through FPN downregulation [94]. DMT1 upregulation has been observed in other animal models of PD, and crucially, in human postmortem brain samples from PD patients [96]. In addition, NEDD4 family-interacting protein 1 (Ndfip1) which is a known regulator of DMT1, is overexpressed in astrocytes of PD patients [97]. Furthermore, Ndfip1 is selectively increased in substantia nigra compared to other regions [97]. Finally, Ndfip1 expression is observed more significantly in neurons with $\alpha$-synuclein deposits [97]. It seems that Ndfip1 upregulation in PD is a homeostatic mechanism which serves to protect neurons from iron toxicity. Ndfip1 upregulation by iron causes DMT1 downregulation, which protects neurons from cellular iron-overload [98]. Knockout of Ndfip1 is accompanied with cellular iron accumulation, oxidative stress and death of dopaminergic neurons [97, 98]. 6-OHDA induces DMT1 upregulation by modulating IRP proteins in neurons [99]. Further evidence concerning the role of DMT1 in PD comes from genetic studies. DMT1 mutations that impair iron-import offer neuroprotection against toxins that cause PD in animal models [96], while certain DMT1 polymorphisms increase the risk for PD [100]. The use of antioxidants reduces the oxidative damage induced by DMT1. Polyphenoles like epigallocatechin3-gallate (EGCG) protect against 6-OHDA neurotoxicity by downregulating hepcidin and DMT1 expression and by upregulating FPN [94]. Iron accumulation in PD is associated with abnormal intracellular protein aggregates named Lewy bodies in substantia nigra [101], while similarly to AD, FPN was shown to be downregulated in PD as well $[102,103]$. Overexpression of FPN in cultured dopaminergic neurons reduces iron-induced oxidative stress [103]. It is interesting to notice that while 6-OHDA induces iron accumulation in neurons, in astrocytes it induces increased iron transport in and out of the cells, which might protect neurons from increased iron-load [104].

\section{Hepcidin in brain ischemia}

Hepcidin disturbance has been observed in brain ischemia [52]. The rationale to study hepcidin is the significant relationship that exists between iron-load and brain damage in this condition [105-108]. There is evidence that excess iron does not originate from blood, at least during focal ischemia [107].

Iron-load during ischemia worsens brain damage by increasing edema and hemorrhage, while the use of iron chelators reverses brain damage [105, 107, 108]. High heme iron intake is also related with stroke risk, while $\mathrm{HH}$ H63D homozygosity is a predictor of increased risk of stroke $[109,110]$. Interestingly, the same mutations are a risk factor for neurodegenerative diseases [84]. Significant hepatic hepcidin disturbance can cause brain ironoverload, as it has been observed in cirrhotic patients [39]. But, in acute conditions, such as acute ischemic stroke and intracerebral hemorrhage, serum hepcidin levels are increased and they contribute to iron-load in ischemic brain [111-114]. What is more, brain damage worsens during ischemia when accompanied with increased systemic hepcidin levels, due to increased brain oxidative injury [18]. Brain hepcidin expression is also elevated during ischemia, and the source of this hepcidin are astrocytes [18]. Upregulation of hepcidin is associated with downregulation of FPN in neurons, but also with decreased iron-efflux from brain endothelial cells into plasma [18]. Studies have revealed the mechanistic pathways that induce hepcidin expression during brain ischemia; they show an important role for TLR4 and their downstream targets (IL6/STAT3 pathway) [18]. 
It is interesting to notice that TLR4 signalling has been consistently linked with brain damage during intracerebral hemorrhage $[18,115,116]$. But, similar to neurodegenerative diseases, iron-efflux blockade together with the increase in iron import will cause iron-overload in ischemic brain. TFR1 is upregulated in brain ischemia due to hypoxia-inducible factor 1-alpha (HIF1- $\alpha$ ) actions [52]. Also, DMT1 upregulation is a consequence of ischemia, while its downregulation offers neuroprotection in models with brain ischemia [117]. Tanshinone IIA is a Chinese herb used in the treatment of cerebrovascular diseases. Its neuroprotective mode of action includes the reduction in the expression of TFR 1 and DMT1, while at the same time it induces overexpression of FPN [118]. That is why in animal models hepcidin treatment during brain ischemia worsens iron-load and brain damage, while hepcidin knockdown ameliorates this damage [18]. Similar results were obtained in mice models with subarachnoid hemorrhage where addition of hepcidin worsened cell apoptosis, while knockdown of hepcidin with siRNA reduced apoptosis significantly [119].

\section{Hepcidin in multiple sclerosis (MS)}

MS is a "classical" neuroinflammatory disease, characterized mainly by a dysregulated activation of adaptive immune system [120]. Iron accumulation has been evidenced early in MS and it progresses during the development of the disease [120, 121]. Iron deposition is observed in active MS lesions and blood vessels, but not in inactive lesions [120]. The source of iron in MS is supposed to be multifactorial; it can originate from degenerated oligodendrocytes, damaged blood vessels or it might occur due to dysregulation of iron transport [120]. Studies suggest that iron accumulation in MS precedes the development of atrophy [122]. Furthermore, brain iron deposition measured with MRI is a better predictor of disability than whole brain atropy [122]. In conclusion, a significant number of studies reveal an important role for iron deposition in the pathophysiology of MS, but still it is not clear if this role is of primary nature.

Iron-chelation has not proved to be a conclusive beneficial therapy in MS, suggesting local changes are more important in the pathophysiology of MS [120, 123]. In favor of this argument is the observation that serum levels of hepcidin, iron and ferritin do not change in MS [124]. Iron-chelation does not seem to be the best option to correct iron dysmetabolism in MS, since iron is needed for myelinization. A more viable option seems to be the downstream effects of iron dysregulation, like increased oxidative stress $[120,123]$. This means that tackling iron dysmetabolism in MS has to be made in a local manner and with specific molecular targeting (local hepcidin?) that would not cause global changes in brain iron metabolism. Small studies have shown specific changes in TFR levels in periplaque white matter of MS patients, while experimental models have shown increased levels of DMT1 in astrocytes around MS lesions [125, 126]. Unfortunately, there are no comprehensive studies that have examined neuronal expression of TFR1 and DMT1 in relation to FPN in MS.

Similarly to AD and PD, inflammatory and hypoxic conditions are present in MS and thought to contribute to iron dysmetabolism [120]. But, if local hepcidin has a role in MS is not known, especially with the lack of studies that have examined the role of this peptide in MS.

\section{Hepcidin in amyotrophic lateral sclerosis (ALS)}

ALS is a motor neuron disease associated with changes in iron metabolism [127]. Ferritin and serum iron are increased in patients with ALS $[128,129]$. Furthermore, ferritin levels are correlated with disease duration [128]. Iron deposition in motor cortex of ALS patients is not primary related to disease pathogenic mechanisms. Microglia in ALS are reported to become iron-loaded due to scavenging of debris created during the primary process of neuron damage $[130,131]$. This increase in iron deposition is partly related to increased TFR1 expression in glial cells [130]. Similarly, neuron iron-load in ALS is related with increase of another iron importer, that is, DMT1 isoform, which expression is not under IRE control, but is under control of inflammatory signals [130]. This is important because inflammation has been observed as an important pathogenic factor in ALS [132]. On the other hand, the expression of FPN in ALS though increased, is still lower than that of DMT1, which would favor iron deposition in cells [130]. Iron-overload seems to be an important player in neuronal damage, since iron-chelation increases life-span and offers neuroprotection in transgenic mice $[130,133]$. Though central nervous system (CNS) actions of hepcidin in ALS have not been evaluated, in transgenic models of this disease serum hepcidin increase is accompanied by FPN downregulation in muscles [134]. But, increased systemic hepcidin cannot explain why FPN downregulation is observed only in certain muscles in ALS. Finally, studies need to address the role of systemic and brain hepcidin in iron dysregulation in ALS through its effects on iron sequestration in brain cells.

\section{Hepcidin in brain cancer}

Hepcidin levels in different brain cancers are generally lower compared to normal tissue with a fairly high degree of heterogeneity found between tumors [69]. But, global changes in the brain might not reveal the exact picture in brain tumors compared to specific cell actions. Glioblastoma stem-like cells (GSCs) are at the apex of 
the hierarchical organization of cells in glioblastoma [135]. These cells can initate, promote and renew brain tumor proliferation. Their high activity in brain cancer has to be maintained with rich supply of nutrients such as iron. This is in-line with results that have shown higher iron-uptake from brain tumor tissue compared to normal tissue [19]. GSCs have the ability to preferentially "steal" iron from their environment by increasing TFR1 expression, that is, iron import [136]. This is probably the reason why hypoxia reverses antiproliferative effects of iron-chelation in brain cancer, since hypoxia in the brain does induce TFR1 expression [52, 137]. But, GSCs might also use hepcidin to increase their cellular iron depots. GSCs show increased levels of ferritin, which is related with increased STAT3 phosphorylation [136]. STAT3 is a known intracellular signaling molecule that induces hepcidin expression [17]. Whether GSCs use hepcidin to increase iron sequestration is an intriguing idea, but has to be validated by future research.

\section{Hepcidin in restless leg syndrome (RLS)}

RLS is a neurological condition with a highly heritable component. It is characterized with an urge to move lower limbs, while many patients show signs of iron deficiency [138]. Iron depots in the brain of RLS patients are low and related with higher expression of brain hepcidin $[139,140]$. Low levels of iron in the brain of RLS patients persists even in the presence of $\mathrm{HH}$ [141]. Furthermore, transferrin receptor expression in the brain microvasculature of RLS patients is low, suggesting low iron transport across the BBB [142]. Still, the role of hepcidin is unclear especially since high levels of brain hepcidin in RLS are accompanied with low levels of hepcidin in CSF [140]. It is interesting to notice that in vitro results show that hepcidin reduces iron-overload only in iron-loaded neurons $[60,61]$. It might be that higher hepcidin levels in the brain of RLS patients occur as a reactive response to protect neurons from iron deficiency by reducing the activity of FPN, though this idea needs confirmation.

\section{Potential role of hepcidin in other brain conditions}

Huntington disease (HD) is a genetic disorder characterized with mutation of the gene encoding for Huntington protein $(\mathrm{Htt})$, which results in the creation of a mutant Htt with toxic properties [143]. HD studies show early destruction of neurons and astrogliosis in the striatum with progressive involvement of cortex and hipoccampus as the disease develops [143]. There is evidence of increased brain iron deposition in this disease, even in the early phases of the disease [144-146], while expression of $\mathrm{Htt}$ in animal models has been shown to be associated with cellular iron homeostasis [143]. There is no compelling evidence that iron-overload in specific structures can serve as the initiator of the disease, but the increase of iron depots as the disease develops shows a role for iron in later stages of the disease. If this role is secondary due to neuronal damage, or it contributes directly in disease progression is still unknown. Although there are no studies that have examined the role of hepcidin in HD, the efficacy of iron-chelation therapy and the observed reactive upregulation of FPN due to neuronal iron-overload suggests that hepcidin downregulation might attenuate neuronal damage [147].

Iron dysregulation has been observed consistently in different organs in Friedreich ataxia (FA) [148]. This disease affects CNS by causing neurodegenerative damages in dentate nuclei of the cerebellum, dorsal root ganglia, but also in cerebrum, thalamus and other structures [149]. FA is caused by a defective frataxin, which main functions include involvement in iron-sulfur cluster formation and in iron delivery to ferrochelatase [148]. Although some observations did find iron accumulation in dentate nuclei in FA patients, other studies have revealed a pattern of iron redistribution, rather than iron accumulation in FA [150]. Studies suggest that iron dysregulation in FA is not needed for neurodegeneration to occur, while animal models reveal tissue-specific damages due to frataxin deficiency $[148,151]$. These differences are related with levels of frataxin expression, where most of the damage is observed in tissues with higher expression of frataxin, such as the heart and dorsal root ganglia [151]. In the heart, inflammatory infiltrate produces hepcidin and has been proposed as one of the pathogenic mechanisms of heart damage in FA [152]. Frataxin deficiency in animal models can cause a strong inflammatory reaction in Schwann cells, which are known to enwrap neurons of dorsal root ganglia [153]. These neurons are frequently affected in FA and are characterized with iron dysregulation and inappropriate myelination [154]. But, hepcidin expression in these cells has not been studied in models of FA, therefore it is not known what role, if any, does hepcidin have in the pathophysiology of neurodegeneration in FA.

\section{Conclusion}

Although data about the role of systemic and local hepcidin in the brain are scarce compared to liver, recent research suggests that hepcidin has important functions in proper brain functioning. Hepcidin in the brain is expressed in low levels, with protein levels being more prominently higher than mRNA expression, suggesting that much of hepcidin in the brain originates from the liver. Studies suggest a high probability that plasma hepcidin crosses BBB, but the real mechanisms behind this transport are not known. Although we know the cellular source of hepcidin in the brain, its regulation is still 


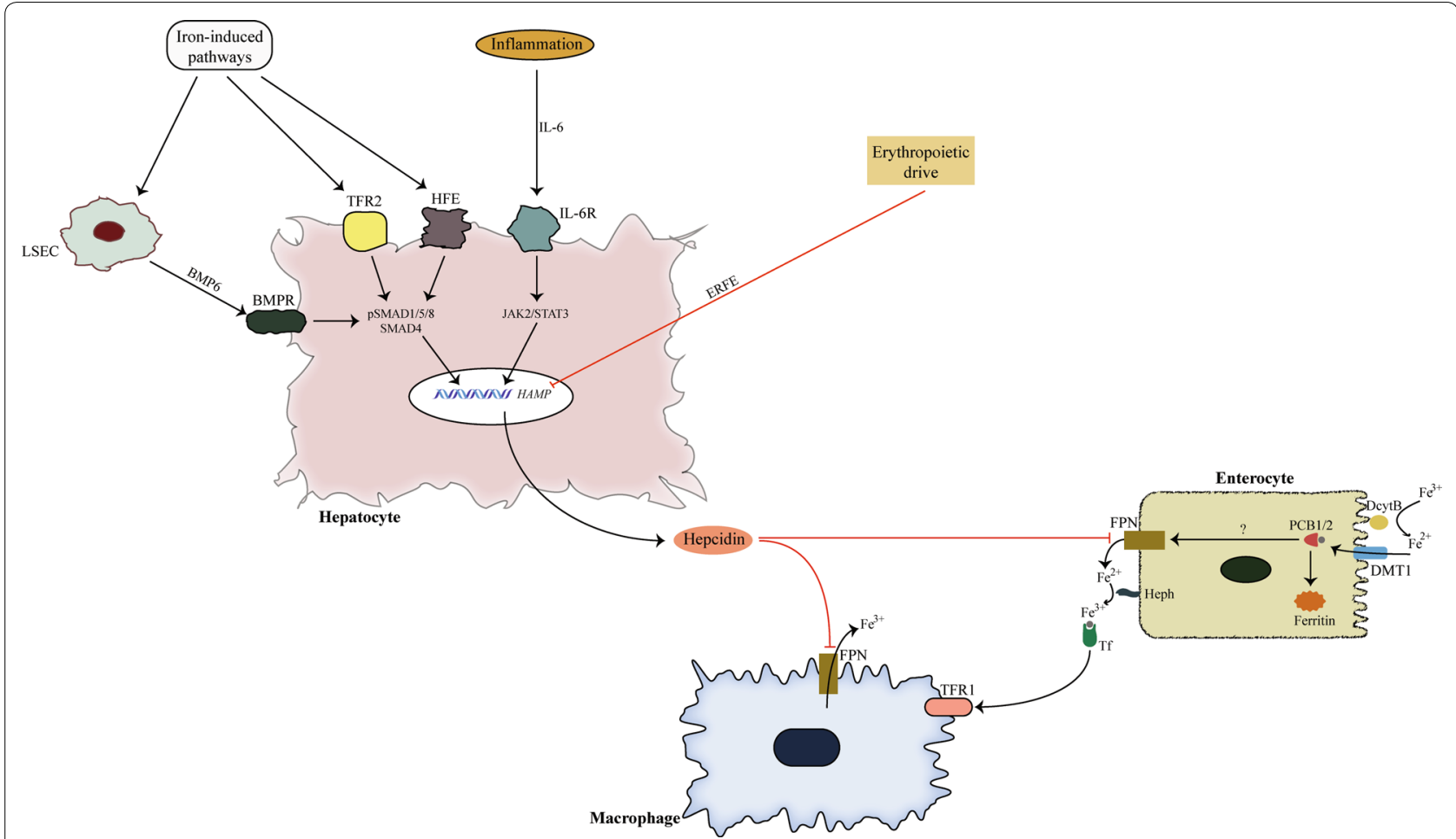

Fig. 1 Systemic iron homeostasis. Trivalent iron is reduced by ferrireductases (DcytB) before its absorption through DMT1 in enterocytes. Once inside enterocytes iron binds with chaperones like PCBs. PCBs act like intracellular iron transporters that distribute this metal to ferritin depots and probably to FPN. FPN is the main exporter of iron out of cells. This action of FPN is helped by ferrioxidases (like Heph). After its export out of cells, iron is immediately bound to Tf. This complex circulates in plasma and finally binds with its target, which is TFR1. Systemic iron availability is controlled by hepcidin. Hepcidin is produced in hepatocytes in response to different stimuli. Iron-mediated pathways are the main factors that induce hepcidin expression. The most important pathways activate LSECs, which in turn produce BMP6. BMP6 acts in a paracrine manner through BMPR in hepatocytes. BMPR activates SMAD pathway, which induces hepcidin expression. Iron pathways induce hepcidin expression through membrane proteins, like TFR2 and HFE, as well. Inflammatory signals are also important upregulators of hepcidin by acting through JAK/STAT pathway. Negative control is realized through ERFE, which is produced from erythrocyte precursors. BMP6 bone morphogenetic protein 6, BMPR BMP receptor, DcytB duodenal cytochrome B, DMT1 divalent metal transporter 1, ERFE erythroferrone, FPN ferroportin, HAMP hepcidin antimicrobial peptide, Heph hephaestin, HFE hemochromatosis protein, JAK2/STAT3 janus kinase 2/signal transducer and activator of transcription 3, LSEC liver sinusoidal endothelial cells, PCB poly-(rC)-binding protein, SMAD S-mothers against decapentaplegic, TFR transferrin receptor

not well understood. Studies suggest that astrocytes and microglia increase hepcidin expression in response to inflammatory stimuli, and probably to iron-load. Data concerning hepcidin expression in neurons in basal conditions are contradictory and still not well understood, though hepcidin expression has been consistently observed in neurons exposed to inflammatory stimuli. Nevertheless, hepcidin does not seem to be important for iron homeostasis in basal conditions, since hepcidin knockout models do not show significant brain ironoverload. Studies suggest that hepcidin therapy protects neurons from iron-overload, but when hepcidin overexpression is observed in the presence of significant inflammatory activity then hepcidin has deleterious effects in neuronal function by inducing iron-overload in neurons. It seems that inflammatory signaling in the brain tips the balance in favor of increased iron-import and cellular iron sequestration. Inflammatory actions accompanied with hepcidin effect in blocking iron-export, further worsens the iron-overload observed in neurons. When inflammation is not present, hepcidin protects from ironoverload due to its role in reducing iron-entry into neurons. In experimental mice models this has already been done with the use of recombinant viruses that contain hepcidin encoding DNA. Recent data suggest that pretreatment with hepcidin has protective functions in neurons. This observation is based on the ability of hepcidin to reduce inflammatory signaling in pretreated cells. This exciting data should be further elucidated.

During ischemia and inflammatory conditions hepcidin expression (mostly from astrocytes) is related with brain damage. The most important data come from models with brain hemorrhage, where hepcidin overload contributes to brain damage. Blocking local and systemic hepcidin in 


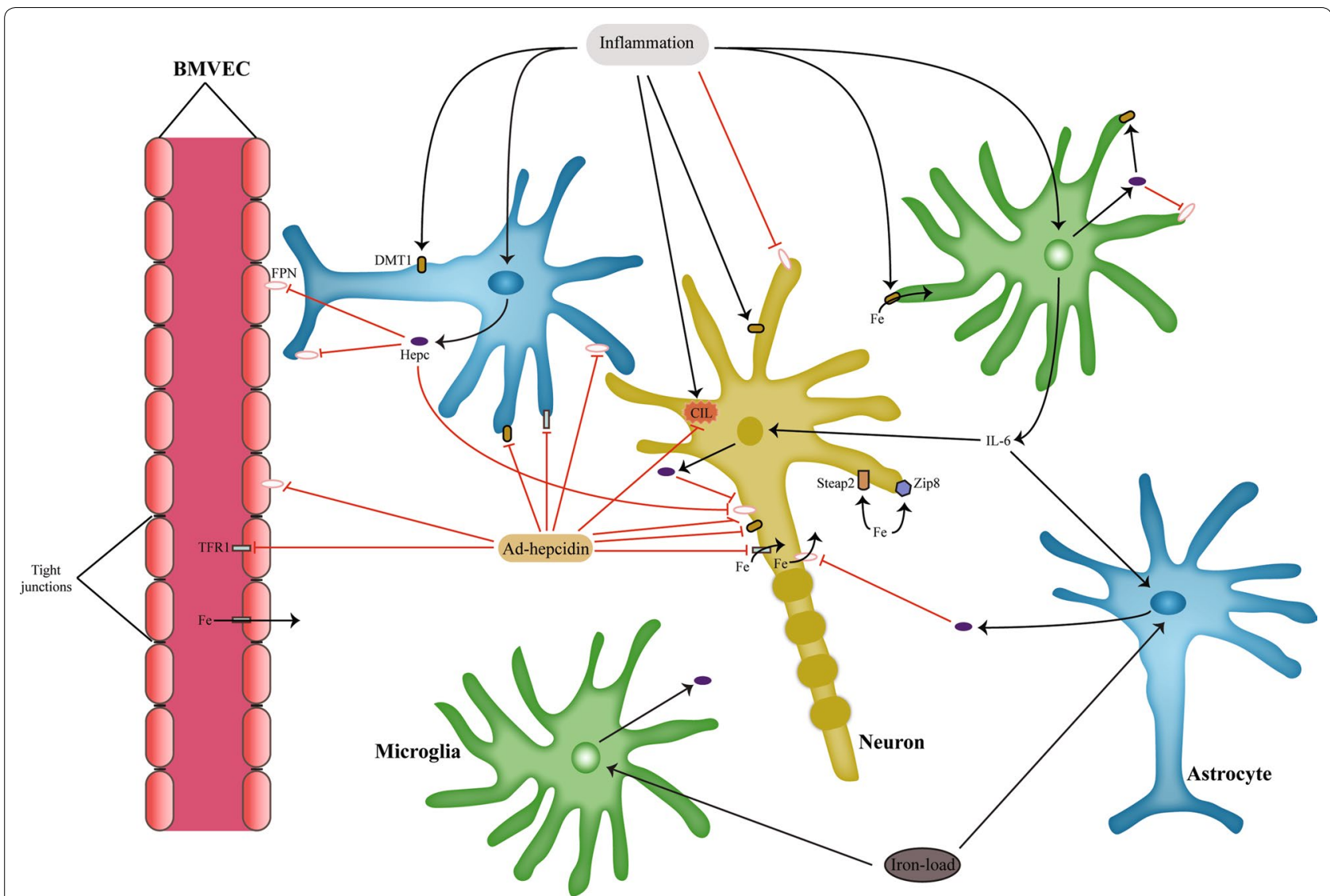

Fig. 2 Hepcidin regulation and action in brain cells. Hepcidin expression in the brain is often induced by inflammatory stimuli. Inflammatory cytokines increase iron import through DMT1, and decrease iron export due to FPN downregulation. This increases cellular iron-load, especially in neurons. During iron-load conditions, astrocytes and microglia have been shown to increase hepcidin production. This might be the case for neurons as well, but the data are still inconclusive. Use of ad-hepcidin protects neurons during iron-overload conditions, by controlling the activity of iron import and export proteins, like TFR1, DMT1, FPN. Also, ad-hepcidin reduces iron flux from BMVEC, which reduces brain iron-load. Recent data suggest an important role for Zip8 and Steap2 for NTBI entry into brain cells. BMVEC brain microvascular endothelial cell, CIL cellular iron-load, DMT1 divalent metal transporter 1, FPN ferroportin, Hepc hepcidin, IL-6 interleukin 6, NTBI non-transferrin bound iron, TFR1 transferrin receptor 1

these conditions ameliorates brain damage. This means that hepcidin therapy can be used to ameliorate brain damage during ischemia. Hepcidin anatagonists are available, and although they have been used mainly for inflammatory anemia characterized with high levels of hepcidin [155], their use in brain tissue has shown that it can downregulate hepcidin expression [156].

There is increasing evidence, albeit circumstantial, that hepcidin might play a role in the pathogenic mechanisms in neurological conditions like AD and PD. Direct role of hepcidin in these conditions, especially in early stages of the disease, has not been studied. Hepcidin disturbance has been observed in other conditions as well, like in brain cancer, where levels of local hepcidin are generally low, but the importance of this observation remains to be unveiled.

In conclusion, hepcidin is expressed in the brain and has important homeostatic functions. Manipulating hepcidin could prove to be a novel therapeutic option in tackling brain damage, especially during brain ischemia/ inflammation and iron-overload.

\section{Abbreviations}

6-OHDA: 6-hidroxydopamine; AD: Alzheimers disease; AMPK: AMP-activated kinase; APP: amyloid precursor protein; AB: amyloid- $\beta$; ALS: amyotrophic lateral sclerosis; BBB: blood-brain barrier; BMPR: BMP receptor; BMP6: bone morphogenetic protein 6; BMVECs: brain microvascular endothelial cells; CNS: central nervous system; CSF: cerebrospinal fluid; CP: ceruloplasmin; DMT1: divalent metal transporter 1; EGCG: epigallocatechin-3-gallate; ERFE: erythroferrone; FPN: ferroportin; FA: Friedreich ataxia; GSCs: glioblastoma stem-like cells; $\mathrm{HH}$ : hemochromatosis; HJV: hemojuvelin; HAMP: hepcidin antimicrobial peptide; Heph: hephaestin; HD: Huntington disease; Htt: Huntington protein; HIF1-a: hypoxia-inducible factor 1-alpha; IL-6: interleukin-6; IRE/IRP: iron regulatory element/iron regulatory protein; JAK2/STAT3: janus kinase 2/signal transducer and activator of transcription 3; LPS: lipopolysaccharide; LSECs: liver sinusoidal endothelial cells; MT2: matriptase 2; MS: multiple sclerosis; Ndfip1: NEDD4 family-interacting protein 1; NTBI: non-transferrin bound iron; PD: Parkinsons disease; PCBPs: poly-(rC)-binding proteins; RLS: restless leg syndrome; RPE: retinal pigment epithelium; SMAD: s-mothers against decapentaplegic; SOCS3: 
suppressor of cytokine signaling 3; TLR4: toll-like receptor 4; Tf: transferrin; TFR1: transferrin receptor 1; TNF-a: tumor necrosis factor-alpha.

\section{Acknowledgements \\ Not applicable.}

\section{Competing interests}

The author declares no competing interests.

\section{Availability of data and materials \\ Not applicable.}

\section{Consent for publication}

Not applicable.

\section{Ethics approval and consent to participate}

Not applicable.

\section{Funding}

Not applicable.

\section{Publisher's Note}

Springer Nature remains neutral with regard to jurisdictional claims in published maps and institutional affiliations.

Received: 6 October 2017 Accepted: 31 January 2018

Published online: 07 February 2018

\section{References}

1. Pigeon C, Ilyin G, Courselaud B, et al. A new mouse liver-specific gene, encoding a protein homologous to human antimicrobial peptide hepcidin, is overexpressed during iron overload. J Biol Chem. 2001;276:7811-9.

2. Lakhal-Littleton S, Wolna M, Chung YJ, et al. An essential cell-autonomous role for hepcidin in cardiac iron homeostasis. Elife. 2016;5:e19804.

3. Tesfay L, Clausen KA, Kim JW, et al. Hepcidin regulation in prostate and its disruption in prostate cancer. Cancer Res. 2015;75:2254-63.

4. Houamel D, Ducrot N, Lefebvre T, et al. Hepcidin as a major component of renal antibacterial defenses against uropathogenic Escherichia coli. J Am Soc Nephrol. 2016;27:835-46.

5. Coffey R, Ganz T. Iron homeostasis: an anthropocentric perspective. J Biol Chem. 2017;292:12727-34.

6. Bogdan AR, Miyazawa M, Hashimoto K, et al. Regulators of iron homeostasis: new players in metabolism, cell death, and disease. Trends Biochem Sci. 2016:41:274-86.

7. Canali S, Zumbrennen-Bullough KB, Core AB, et al. Endothelial cells produce bone morphogenetic protein 6 required for iron homeostasis in mice. Blood. 2017;129:405-14.

8. Steinbicker AU, Bartnikas TB, Lohmeyer LK, et al. Perturbation of hepcidin expression by BMP type I receptor deletion induces iron overload in mice. Blood. 2011;118:4224-30

9. Zhao N, Maxson JE, Zhang RH, et al. Neogenin facilitates the induction of hepcidin expression by hemojuvelin in the liver. J Biol Chem. 2016:291:12322-35.

10. Wallace DF, Summerville L, Crampton EM, et al. Combined deletion of Hfe and transferrin receptor 2 in mice leads to marked dysregulation of hepcidin and iron overload. Hepatology. 2009;50:1992-2000.

11. Vadhan-Raj S, Abonour R, Goldman JW, et al. A first-in-human phase 1 study of a hepcidin monoclonal antibody, LY2787106, in cancerassociated anemia. J Hematol Oncol. 2017;10:73.

12. Kautz $L$, Jung $G$, Valore $E V$, et al. Identification of erythroferrone as an erythroid regulator of iron metabolism. Nat Genet. 2014;46:678-84.

13. Bacchetta J, Zaritsky JJ, Sea JL, et al. Suppression of iron-regulatory hepcidin by vitamin D. J Am Soc Nephrol. 2014;25:564-72.
14. Sonnweber T, Nachbaur D, Schroll A, et al. Hypoxia induced downregulation of hepcidin is mediated by platelet derived growth factor BB. Gut. 2014;63:1951-9.

15. Poli M, Girelli D, Campostrini N, et al. Heparin: a potent inhibitor of hepcidin expression in vitro and in vivo. Blood. 2011;117:997-1004.

16. Lehtihet $M$, Bonde $Y$, Beckman L, et al. Circulating hepcidin-25 Is reduced by endogenous estrogen in humans. PLOS ONE. 2016;11:e0148802.

17. Ganz T. Hepcidin and iron regulation, 10 years later. Blood. 2011;117:4425-33.

18. Xiong $X-Y$, Liu L, Wang F-X, et al. Toll-like receptor 4/MyD88-mediated signaling of hepcidin expression causing brain iron accumulation, oxidative injury, and cognitive impairment after intracerebral hemorrhage, clinical perspective. Circulation. 2016;134:1025-38.

19. Roelckel U, Leenders KL, von Ammon K, et al. Brain tumor iron uptake measured with positron emission tomography and 52Fe-citrate. J Neurooncol. 1996;29:157-65.

20. McCarthy RC, Kosman DJ. Mechanisms and regulation of iron trafficking across the capillary endothelial cells of the blood-brain barrier. Front Mol Neurosci. 2015:8:31

21. McCarthy RC, Kosman DJ. Iron transport across the blood-brain barrier: development, neurovascular regulation and cerebral amyloid angiopathy. Cell Mol Life Sci. 2015;72:709-27.

22. Bien-Ly N, Yu YJ, Bumbaca D, et al. Transferrin receptor (TfR) trafficking determines brain uptake of TfR antibody affinity variants. J Exp Med. 2014;211:233-44.

23. Rouault TA, Cooperman S. Brain iron metabolism. Semin Pediatr Neurol. 2006;13:142-8.

24. McCarthy RC, Kosman DJ. Glial cell ceruloplasmin and hepcidin differentially regulate iron efflux from brain microvascular endothelial cells. PLOS ONE. 2014:9:e89003.

25. Codazzi F, Pelizzoni I, Zacchetti D, et al. Iron entry in neurons and astrocytes: a link with synaptic activity. Front Mol Neurosci. 2015;8:18.

26. Dringen R, Bishop GM, Koeppe M, et al. The pivotal role of astrocytes in the metabolism of iron in the brain. Neurochem Res. 2007:32:1884-90.

27. Pelizzoni I, Zacchetti D, Campanella A, et al. Iron uptake in quiescent and inflammation-activated astrocytes: a potentially neuroprotective control of iron burden. Biochim Biophys Acta Mol Basis Dis. 2013;1832:1326-33

28. Salvador GA. Iron in neuronal function and dysfunction. BioFactors. 2010;36:103-10

29. Skjørringe T, Burkhart A, Johnsen KB, et al. Divalent metal transporter 1 (DMT1) in the brain: implications for a role in iron transport at the blood-brain barrier, and neuronal and glial pathology. Front Mol Neurosci. 2015:8:19.

30. Ji C, Kosman DJ. Molecular mechanisms of non-transferrin-bound and transferrin-bound iron uptake in primary hippocampal neurons. Neurochem. 2015;133:668-83.

31. Krause A, Neitz S, Mägert HJ, et al. LEAP-1, a novel highly disulfidebonded human peptide, exhibits antimicrobial activity. FEBS Lett. 2000:480:147-50

32. Zechel S, Huber-Wittmer K, von Bohlen und Halbach O. Distribution of the iron-regulating protein hepcidin in the murine central nervous system. J Neurosci Res. 2006;84:790-800

33. Raha-Chowdhury R, Raha AA, Forostyak $S$, et al. Expression and cellular localization of hepcidin mRNA and protein in normal rat brain. BMC Neurosci. 2015:16:24.

34. Wang S-M, Fu L-J, Duan X-L, et al. Role of hepcidin in murine brain iron metabolism. Cell Mol Life Sci. 2010;67:123-33.

35. Raha AA, Vaishnav RA, Friedland RP, et al. The systemic iron-regulatory proteins hepcidin and ferroportin are reduced in the brain in Alzheimer's disease. Acta Neuropathol Commun. 2013:1:55.

36. Rutgers MP, Pielen A, Gille M. Chronic cerebellar ataxia and hereditary hemochromatosis: causal or coincidental association? J Neurol. 2007;254:1296-7.

37. Nielsen JE, Jensen LN, Krabbe K. Hereditary haemochromatosis: a case of iron accumulation in the basal ganglia associated with a parkinsonian syndrome. J Neurol Neurosurg Psychiatry. 1995:59:318-21.

38. Miyasaki K, Murao S, Koizumi N. Hemochromatosis associated with brain lesions - a disorder of trace-metal binding proteins and/or polymers? J Neuropathol Exp Neurol. 1977;36:964-76. 
39. Lin D, Ding J, Liu J-Y, et al. Decreased serum hepcidin concentration correlates with brain iron deposition in patients with HBV-related cirrhosis. PLoS ONE. 2013;8:e65551.

40. Aguirre P, Mena N, Tapia V, et al. Iron homeostasis in neuronal cells: a role for IREG1. BMC Neurosci. 2005;6:3.

41. Schluesener H, Meyermann R. Neutrophilic defensins penetrate the blood-brain barrier. J Neurosci Res. 1995:42:718-23.

42. Stalmans S, Bracke N, Wynendaele E, et al. Cell-penetrating peptides selectively cross the blood-brain barrier in vivo. PLoS ONE. 2015;10:e0139652.

43. Gnana-Prakasam JP, Martin PM, Mysona BA, et al. Hepcidin expression in mouse retina and its regulation via lipopolysaccharide/Toll-like receptor-4 pathway independent of Hfe. Biochem J. 2008;411:79-88.

44. Hadziahmetovic M, Song Y, Wolkow N, et al. Bmp6 regulates retinal iron homeostasis and has altered expression in age-related macular degeneration. Am J Pathol. 2011;179:335-48.

45. Hadziahmetovic M, Song Y, Ponnuru P, et al. Age-dependent retinal iron accumulation and degeneration in hepcidin knockout mice. Investig Ophthalmol Vis Sci. 2011;52:109-18.

46. Gnana-Prakasam JP, Tawfik A, Romej M, et al. Iron-mediated retinal degeneration in haemojuvelin-knockout mice. Biochem J. 2012:441:599-608.

47. Bardou-Jacquet E, Ben Ali Z, Beaumont-Epinette M-P, et al. Non-HFE hemochromatosis: pathophysiological and diagnostic aspects. Clin Res Hepatol Gastroenterol. 2014;38:143-54.

48. Zerbib J, Pierre-Kahn V, Sikorav A, et al. Unusual retinopathy associated with hemochromatosis. Retin Cases Brief Rep. 2015:9:190-4.

49. Theurl M, Song D, Clark E, et al. Mice with hepcidin-resistant ferroportin accumulate iron in the retina. FASEB J. 2016:30:813-23.

50. Lieblein-Boff JC, MCKim DB, Shea DT, et al. Neonatal E. coli infection causes neuro-behavioral deficits associated with hypomyelination and neuronal sequestration of iron. J Neurosci. 2013;33:16334-45.

51. Marques F, Falcao AM, Sousa JC, et al. Altered iron metabolism is part of the choroid plexus response to peripheral inflammation. Endocrinology. 2009; 150:2822-8.

52. Ding $\mathrm{H}$, Yan $\mathrm{C}-\mathrm{Z}$, Shi $\mathrm{H}$, et al. Hepcidin is involved in iron regulation in the ischemic brain. PLoS ONE. 2011;6:e25324.

53. Wang Q, Du F, Qian Z-M, et al. Lipopolysaccharide induces a significant increase in expression of iron regulatory hormone hepcidin in the cortex and substantia nigra in rat brain. Endocrinology. 2008;149:3920-5.

54. You L-H, Yan C-Z, Zheng B-J, et al. Astrocyte hepcidin is a key factor in LPS-induced neuronal apoptosis. Cell Death Dis. 2017;8:e2676.

55. Qian Z-M, He X, Liang T, et al. Lipopolysaccharides upregulate hepcidin in neuron via microglia and the IL-6/STAT3 signaling pathway. Mol Neurobiol. 2014;50:811-20.

56. Urrutia P, Aguirre P, Esparza A, et al. Inflammation alters the expression of DMT1, FPN1 and hepcidin, and it causes iron accumulation in central nervous system cells. J Neurochem. 2013;126:541-9.

57. Li W-Y, Li F-M, Zhou Y-F, et al. Aspirin down regulates hepcidin by inhibiting NF-KB and IL6/JAK2/STAT3 pathways in BV-2 microglial cells treated with lipopolysaccharide. Int J Mol Sci. 2016;17:1921.

58. Du F, Qian C, Ming Qian Z, et al. Hepcidin directly inhibits transferrin receptor 1 expression in astrocytes via a cyclic AMP-protein kinase a pathway. Glia. 2011;59:936-45.

59. Du F, Qian Z-M, Luo Q, et al. Hepcidin suppresses brain iron accumulation by downregulating iron transport proteins in iron-overloaded rats. Mol Neurobiol. 2015;52:101-14.

60. Gong J, Du F, Qian ZM, et al. Pre-treatment of rats with ad-hepcidin prevents iron-induced oxidative stress in the brain. Free Radic Biol Med. 2016;90:126-32

61. Zhou Y-F, Zhang C, Yang G, et al. Hepcidin protects neuron from hemin-mediated injury by reducing iron. Front Physiol. 2017;8:332.

62. Rathore KI, Redensek A, David S. Iron homeostasis in astrocytes and microglia is differentially regulated by TNF- $a$ and TGF- $\beta 1$. Glia. 2012:60:738-50.

63. Zhang Z, Hou L, Song J-L, et al. Pro-inflammatory cytokine-mediated ferroportin down-regulation contributes to the nigral iron accumulation in lipopolysaccharide-induced Parkinsonian models. Neuroscience. 2014:257:20-30.
64. Sun C, Song N, Xie A, et al. High hepcidin level accounts for the nigral iron accumulation in acute peripheral iron intoxication rats. Toxicol Lett. 2012:212:276-81.

65. Urrutia PJ, Hirsch EC, González-Billault C, et al. Hepcidin attenuates amyloid beta-induced inflammatory and pro-oxidant responses in astrocytes and microglia. J Neurochem. 2017;142:140-52.

66. De Domenico I, Zhang TY, Koening CL, et al. Hepcidin mediates transcriptional changes that modulate acute cytokine-induced inflammatory responses in mice. J Clin Investig. 2010;120:2395-405.

67. Burté F, Brown BJ, Orimadegun AE, et al. Circulatory hepcidin is associated with the anti-inflammatory response but not with iron or anemic status in childhood malaria. Blood. 2013;121:3016-22.

68. Simpson IA, Ponnuru P, Klinger ME, et al. A novel model for brain iron uptake: introducing the concept of regulation. J Cereb Blood Flow Metab. 2015:35:48-57.

69. Hänninen MM, Haapasalo J, Haapasalo H, et al. Expression of ironrelated genes in human brain and brain tumors. BMC Neurosci. 2009;10:36.

70. Rodriguez Martinez A, Niemela O, Parkkila S. Hepatic and extrahepatic expression of the new iron regulatory protein hemojuvelin. Haematologica. 2004;89:1441-5.

71. Wang Y, Chang C-F, Morales M, et al. Bone morphogenetic protein-6 reduces ischemia-induced brain damage in rats. Stroke. 2001;32:2170-8.

72. Crews L, Adame A, Patrick C, et al. Increased BMP6 levels in the brains of Alzheimer's disease patients and APP transgenic mice are accompanied by impaired neurogenesis. J Neurosci. 2010;30:12252-62.

73. Pellegrino RM, Boda E, Montarolo F, et al. Transferrin receptor 2 dependent alterations of brain iron metabolism affect anxiety circuits in the mouse. Sci Rep. 2016;6:30725.

74. Benkovic SA, Connor JR. Ferritin, transferrin, and iron in selected regions of the adult and aged rat brain. J Comp Neurol. 1993;338:97-113.

75. Belaidi AA, Bush Al. Iron neurochemistry in Alzheimer's disease and Parkinson's disease: targets for therapeutics. J Neurochem. 2016;139:179-97.

76. Lu LN, Qian ZM, Wu KC, et al. Expression of iron transporters and pathological hallmarks of Parkinson's and Alzheimer's diseases in the brain of young, adult, and aged rats. Mol Neurobiol. 2017;54:5213-24.

77. Hofer T, Perry G. Nucleic acid oxidative damage in Alzheimer's disease-explained by the hepcidin-ferroportin neuronal iron overload hypothesis? J Trace Elem Med Biol. 2016;38:1-9.

78. Nunomura A, Perry G, Aliev G, et al. Oxidative damage is the earliest event in Alzheimer disease. J Neuropathol Exp Neurol. 2001;60:759-67.

79. Smith MA, Zhu $X$, Tabaton M, et al. Increased iron and free radical generation in preclinical Alzheimer disease and mild cognitive impairment. J Alzheimers Dis. 2010;19:363-72.

80. Raven EP, Lu PH, Tishler TA, et al. Increased iron levels and decreased tissue integrity in hippocampus of Alzheimer's disease detected in vivo with magnetic resonance imaging. J Alzheimers Dis. 2013;37:127-36.

81. Bartzokis G, Sultzer D, Cummings J, et al. In vivo evaluation of brain iron in Alzheimer disease using magnetic resonance imaging. Arch Gen Psychiatry. 2000;57:47.

82. Skjørringe T, Møller LB, Moos T. Impairment of interrelated iron- and copper homeostatic mechanisms in brain contributes to the pathogenesis of neurodegenerative disorders. Front Pharmacol. 2012;3:169.

83. Rottkamp CA, Raina AK, Zhu X, et al. Redox-active iron mediates amyloid-beta toxicity. Free Radic Biol Med. 2001;30:447-50.

84. Peters DG, Connor JR, Meadowcroft MD. The relationship between iron dyshomeostasis and amyloidogenesis in Alzheimer's disease: two sides of the same coin. Neurobiol Dis. 2015:81:49-65.

85. Duce JA, Tsatsanis A, Cater MA, et al. Iron-export ferroxidase activity of $\beta$-amyloid precursor protein is inhibited by zinc in Alzheimer's disease. Cell. 2010;142:857-67.

86. Wong BX, Tsatsanis A, Lim LQ, et al. $\beta$-Amyloid precursor protein does not possess ferroxidase activity but does stabilize the cell surface ferrous iron exporter ferroportin. PLoS ONE. 2014;9:e114174.

87. Zheng W, Xin N, Chi Z-H, et al. Divalent metal transporter 1 is involved in amyloid precursor protein processing and A generation. FASEB J. 2009:23:4207-17. 
88. Crespo ÂC, Silva B, Marques L, et al. Genetic and biochemical markers in patients with Alzheimer's disease support a concerted systemic iron homeostasis dysregulation. Neurobiol Aging. 2014;35:777-85.

89. Sternberg Z, Hu Z, Sternberg D, et al. Serum hepcidin levels, iron dyshomeostasis and cognitive loss in Alzheimer's disease. Aging Dis. 2017;8:215-27.

90. Wang J-Y, Zhuang Q-Q, Zhu L-B, et al. Meta-analysis of brain iron levels of Parkinson's disease patients determined by postmortem and MRI measurements. Sci Rep. 2016;6:36669.

91. Guan X, Xuan M, Gu Q, et al. Regionally progressive accumulation of iron in Parkinson's disease as measured by quantitative susceptibility mapping. NMR Biomed. 2017;30:e3489.

92. Brar S, Henderson D, Schenck J, et al. Iron accumulation in the substantia nigra of patients with Alzheimer disease and parkinsonism. Arch Neurol. 2009;66:224-36.

93. Freed J, Chakrabarti L. Defining a role for hemoglobin in Parkinson's disease. npj Park Dis. 2016;2:16021

94. Chen D, Kanthasamy AG, Reddy MB. EGCG protects against 6-OHDAinduced neurotoxicity in a cell culture model. Parkinsons Dis. 2015;2015:843906.

95. Xu Q, Kanthasamy AG, Jin H, et al. Hepcidin plays a key role in 6-OHDA induced iron overload and apoptotic cell death in a cell culture model of Parkinson's disease. Parkinsons Dis. 2016;2016:8684130.

96. Salazar J, Mena N, Hunot S, et al. Divalent metal transporter 1 (DMT1) contributes to neurodegeneration in animal models of Parkinson's disease. Proc Natl Acad Sci USA. 2008;105:18578-83.

97. Howitt J, Gysbers AM, Ayton S, et al. Increased Ndfip1 in the substantia nigra of Parkinsonian brains is associated with elevated iron levels. PLoS ONE. 2014;9:e87119.

98. Howitt J, Putz U, Lackovic J, et al. Divalent metal transporter 1 (DMT1) regulation by Ndfip1 prevents metal toxicity in human neurons. Proc Natl Acad Sci USA. 2009;106:15489-94.

99. Jiang $\mathrm{H}$, Song $\mathrm{N}$, $\mathrm{Xu} \mathrm{H}$, et al. Up-regulation of divalent metal transporter 1 in 6-hydroxydopamine intoxication is IRE/IRP dependent. Cell Res. 2010;20:345-56

100. He Q, DuT, Yu X, et al. DMT1 polymorphism and risk of Parkinson's disease. Neurosci Lett. 2011;501:128-31.

101. Castellani RJ, Siedlak SL, Perry G, et al. Sequestration of iron by Lewy bodies in Parkinson's disease. Acta Neuropathol. 2000;100:111-4.

102. Song N, Wang J, Jiang H, et al. Ferroportin 1 and hephaestin overexpression attenuate iron-induced oxidative stress in MES23.5 dopaminergic cells. J Cell Biochem. 2010;110:1063-72.

103. Song N, Wang J, Jiang H, et al. Ferroportin 1 but not hephaestin contributes to iron accumulation in a cell model of Parkinson's disease. Free Radic Biol Med. 2010;48:332-41.

104. Zhang H-Y, Wang N-D, Song N, et al. 6-Hydroxydopamine promotes iron traffic in primary cultured astrocytes. Biometals. 2013;26:705-14.

105. Garton T, Keep RF, Hua Y, et al. Brain iron overload following intracranial haemorrhage. Stroke Vasc Neurol. 2016;1:172-84.

106. García-Yébenes I, Sobrado M, Moraga A, et al. Iron overload, measured as serum ferritin, increases brain damage induced by focal ischemia and early reperfusion. Neurochem Int. 2012;61:1364-9.

107. Mehdiratta M, Kumar S, Hackney D, et al. Association between serum ferritin level and perihematoma edema volume in patients with spontaneous intracerebral hemorrhage. Stroke. 2008;39:1165-70.

108. Millerot-Serrurot E, Bertrand N, Mossiat C, et al. Temporal changes in free iron levels after brain ischemia. Neurochem Int. 2008:52:1442-8.

109. Kaluza J, Wolk A, Larsson SC. Heme iron intake and risk of stroke. Stroke. 2013:44:334-9.

110. Ellervik C, Tybjaerg-Hansen A, Appleyard M, et al. Hereditary hemochromatosis genotypes and risk of ischemic stroke. Neurology. 2007;68:1025-31.

111. Azab SF, Akeel NE, Abdalhady MA, et al. Serum hepcidin levels in childhood-onset ischemic stroke. Medicine. 2016;95:e2921.

112. Słomka A, Świtońska M, Żekanowska E. Hepcidin levels are increased in patients with acute ischemic stroke: preliminary report. J Stroke Cerebrovasc Dis. 2015;24:1570-6.

113. Petrova J, Manolov $\mathrm{V}$, Vasilev $\mathrm{V}$, et al. Ischemic stroke, inflammation, iron overload-connection to a hepcidin. Int J Stroke. 2016;11:NP16-7.
114. Xiong $X-Y$, Chen J, Zhu W-Y, et al. Serum hepcidin concentrations correlate with serum iron level and outcome in patients with intracerebral hemorrhage. Neurol Sci. 2015;36:1843-9.

115. Sansing LH, Harris TH, Welsh FA, et al. Toll-like receptor 4 contributes to poor outcome after intracerebral hemorrhage. Ann Neurol. 2011;70:646-56

116. Lin S, Yin Q, Zhong Q, et al. Heme activates TLR4-mediated inflammatory injury via MyD88/TRIF signaling pathway in intracerebral hemorrhage. J Neuroinflamm. 2012;9:46.

117. Ingrassia R, Lanzillotta A, Sarnico I, et al. 1B/(-)IRE DMT1 expression during brain ischemia contributes to cell death mediated by NF-KB/ RelA acetylation at Lys310. PLoS ONE. 2012;7:e38019.

118. Yang $L$, Zhang $B$, Yin $L$, et al. Tanshinone IIA prevented brain iron dyshomeostasis in cerebral ischemic rats. Cell Physiol Biochem. 2011;27:23-30.

119. Tan G, Liu L, He Z, et al. Role of hepcidin and its downstream proteins in early brain injury after experimental subarachnoid hemorrhage in rats. Mol Cell Biochem. 2016:418:31-8.

120. Heppner FL, Ransohoff RM, Becher B. Immune attack: the role of inflammation in Alzheimer disease. Nat Rev Neurosci. 2015;16:358-72.

121. Ceccarelli A, Filippi M, Neema M, et al. T2 hypointensity in the deep gray matter of patients with benign multiple sclerosis. Mult Scler J. 2009;15:678-86.

122. Stankiewicz JM, Neema M, Ceccarelli A. Iron and multiple sclerosis. Neurobiol Aging. 2014;35:S51-8.

123. van Rensburg SJ, Kotze MJ, van Toorn R. The conundrum of iron in multiple sclerosis-time for an individualised approach. Metab Brain Dis. 2012;27:239-53.

124. Ellidag HY, Kurtulus F, Yaman A, et al. Serum iron metabolism markers including hepcidin in multiple sclerosis patients. Neurochem J. 2014;8:226-30

125. Hametner S, Wimmer I, Haider L, et al. Iron and neurodegeneration in the multiple sclerosis brain. Ann Neurol. 2013;74:848-61.

126. Zarruk JG, Berard JL, Passos dos Santos R, et al. Expression of iron homeostasis proteins in the spinal cord in experimental autoimmune encephalomyelitis and their implications for iron accumulation. Neurobiol Dis. 2015;81:93-107.

127. Gajowiak A, Styś A, Starzyński RR, et al. Mice overexpressing both nonmutated human SOD1 and mutated SOD1G93A genes: a competent experimental model for studying iron metabolism in amyotrophic lateral sclerosis. Front Mol Neurosci. 2016;8:82.

128. Su XW, Simmons Z, Mitchell RM, et al. Biomarker-based predictive models for prognosis in amyotrophic lateral sclerosis. JAMA Neurol. 2013:31:703-6.

129. Veyrat-Durebex C, Corcia P, Mucha A, et al. Iron metabolism disturbance in a French cohort of ALS patients. Biomed Res Int. 2014;2014:485723.

130. Jeong SY, Rathore Kl, Schulz K, et al. Dysregulation of iron homeostasis in the CNS contributes to disease progression in a mouse model of amyotrophic lateral sclerosis. J Neurosci. 2009;29:610-9.

131. Kwan JY, Jeong SY, Van Gelderen P, et al. Iron accumulation in deep cortical layers accounts for MRI signal abnormalities in ALS: correlating 7 tesla MRI and pathology. PLoS ONE. 2012;7:e35241.

132. Lovejoy DB, Guillemin GJ. The potential for transition metal-mediated neurodegeneration in amyotrophic lateral sclerosis. Front Aging Neurosci. 2014:6:173.

133. Wang Q, Zhang X, Chen S, et al. Prevention of motor neuron degeneration by novel iron chelators in SOD1(G93A) transgenic mice of amyotrophic lateral sclerosis. Neurodegener Dis. 2011;8:310-21.

134. Halon M, Kaczor JJ, Ziolkowski W, et al. Changes in skeletal muscle iron metabolism outpace amyotrophic lateral sclerosis onset in transgenic rats bearing the G93A hmSOD1 gene mutation. Free Radic Res. 2014:48:1363-70.

135. Yi Y, Hsieh I-Y, Huang X, et al. Glioblastoma stem-like cells: characteristics, microenvironment, and therapy. Front Pharmacol. 2016;7:477.

136. Schonberg DL, Miller TE, Wu Q, et al. Preferential iron trafficking characterizes glioblastoma stem-like cells. Cancer Cell. 2015;28:441-55.

137. Legendre C, Avril S, Guillet C. Low oxygen tension reverses antineoplastic effect of iron chelator deferasirox in human glioblastoma cells. BMC Cancer. 2016;16:51 
138. Weinstock LB, Walters AS, Paueksakon P. Restless legs syndrome-theoretical roles of inflammatory and immune mechanisms. Sleep Med Rev. 2012;16:341-54.

139. Rizzo G, Manners D, Testa $C$, et al. Low brain iron content in idiopathic restless legs syndrome patients detected by phase imaging. Mov Disord. 2013;28:1886-90.

140. Clardy SL, Wang X, Boyer PJ, et al. Is ferroportin-hepcidin signaling altered in restless legs syndrome? J Neurol Sci. 2006;247:173-9.

141. Haba-Rubio J, Staner L, Petiau C, et al. Restless legs syndrome and low brain iron levels in patients with haemochromatosis. J Neurol Neurosurg Psychiatry. 2005;76:1009-10.

142. Connor JR, Ponnuru P, Wang X-S, et al. Profile of altered brain iron acquisition in restless legs syndrome. Brain. 2011;134:959-68.

143. Muller M, Leavitt BR. Iron dysregulation in Huntington's disease. J Neurochem. 2014;130:328-50.

144. van Bergen JMG, Hua J, Unschuld PG, et al. Quantitative susceptibility mapping suggests altered brain iron in premanifest Huntington disease. AJNR Am J Neuroradiol. 2016:37:789-96.

145. Phillips O, Squitieri F, Sanchez-Castaneda C, et al. The corticospinal tract in Huntington's disease. Cereb Cortex. 2015;25:2670-82

146. Bartzokis G, Cummings J, Perlman S, et al. Increased basal ganglia iron levels in Huntington disease. Arch Neurol. 1999:56:569.

147. Chen J, Marks E, Lai B, et al. Iron accumulates in Huntington's disease neurons: protection by deferoxamine. PLoS ONE. 2013:8:e77023.
148. Anzovino A, Lane DJR, Huang ML-H, et al. Fixing frataxin: "ironing out" the metabolic defect in Friedreich's ataxia. Br J Pharmacol. 2014:171:2174-90

149. Selvadurai LP, Harding $\mathrm{H}$, Corben LA, et al. Cerebral abnormalities in Friedreich ataxia: a review. Neurosci Biobehav Rev. 2017. https://doi. org/10.1016/j.neubiorev.2017.08.006.

150. Koeppen AH, Ramirez RL, Yu D, et al. Friedreich's ataxia causes redistribution of iron, copper, and zinc in the dentate nucleus. Cerebellum. 2012:11:845-60.

151. Santos R, Lefevre S, Sliwa D, et al. Friedreich ataxia: molecular mechanisms, redox considerations, and therapeutic opportunities. Antioxid Redox Signal. 2010;13:651-90.

152. Koeppen $A H$, Ramirez RL, Becker AB, et al. The pathogenesis of cardiomyopathy in Friedreich ataxia. PLoS ONE. 2015;10:e0116396.

153. Lu C, Schoenfeld R, Shan Y, et al. Frataxin deficiency induces Schwann cell inflammation and death. Biochim Biophys Acta Mol Basis Dis. 2009;1792:1052-61

154. Koeppen AH, Morral JA, Davis AN, et al. The dorsal root ganglion in Friedreich's ataxia. Acta Neuropathol. 2009;118:763-76.

155. Crielaard BJ, Lammers T, Rivella S. Targeting iron metabolism in drug discovery and delivery. Nat Rev Drug Discov. 2017;16:400-23.

156. Farajdokht F, Soleimani M, Mehrpouya S, et al. The role of hepcidin in chronic mild stress-induced depression. Neurosci Lett. 2015;588:120-4.

\section{Submit your next manuscript to BioMed Central and we will help you at every step:}

- We accept pre-submission inquiries

- Our selector tool helps you to find the most relevant journal

- We provide round the clock customer support

- Convenient online submission

- Thorough peer review

- Inclusion in PubMed and all major indexing services

- Maximum visibility for your research

Submit your manuscript at www.biomedcentral.com/submit 